\title{
An Industrial Application of Resource Constrained Scheduling for Quick Changeover
}

\author{
R. M. Sousa, R. M. Lima, J. D. Carvalho, A. C. Alves \\ Department of Production and Systems, University of Minho, Guimarães, Portugal \\ ( $\{\mathrm{rms}, \mathrm{rml}$, dinis, anabela\}@dps.uminho.pt)
}

\begin{abstract}
This paper describes the improvement of the quick changeover process of a painting line in a wooden frames factory. The well-known SMED technique (Single Minute Exchange of Die) was applied. However the characteristics of the setup operations (those characteristics also occur in other industrial changeover scenarios) have revealed the possibility of advantageous utilization of resource constrained project scheduling methods. The application of one of these methods represents an innovative contribution to the quick changeover area, allowing (when applicable) the scheduling of the involved setup operations, considering their duration, precedence relations and resources' need, in order to achieve a reduced setup time.
\end{abstract}

Keywords - Brooks' algorithm, quick changeover, resource constrained scheduling, setup time, SMED

\section{INTRODUCTION}

One of the most common aims of any industrial company has always been the improvement of its production system performance, in order to achieve high quality products, low costs and reduced delivery times. However, and at least over the last years, the markets are imposing additional demands: customized products and orders of very small quantities (eventually unitary). A significant number of traditional production systems is oriented to mass production (large quantities of a small diversity of products) and, thus, they must adapt to the new tendencies (small quantities of a large diversity of products). To face this challenge some paradigms have emerged, e.g.: mass customization production [1] and customer oriented production [2]. In any case, the new production systems must adapt to a different lot of different products as many times as needed. The immediate implication is a dramatic increase on the number of changeover occurrences. It is obvious that setup times as short as possible are a necessary condition (but not sufficient) to achieve the referred goals.

This paper describes the development and implementation of a quick changeover process, using a resource constrained project scheduling method - the Brooks' algorithm [3, 4] -, for a painting line of a wooden frame company (the choice of this heuristic algorithm is explained in the next section). This company was accustomed to orders of hundreds, and even thousands, of meters of a relatively small number of different wooden frames. However, progressively, those large orders are disappearing, being replaced by a much higher number of orders of very small quantities (e.g. 10 meters) of a large number of different wooden frames. Besides the obvious intended setup time reduction, the paper objective is to demonstrate how the Brooks' algorithm (BAG) can be effectively used in some changeover scenarios. This is an innovative contribution as no references were found about the conjunct application of SMED and BAG. As example of a another innovation, [5] describes a quick changeover implementation (in an assembly line of car radios) that goes beyond the usual SMED application by assuring not only a fast setup process but also the availability of the components/materials necessary to feed the assembly line.

The paper is structured in five sections. After the introduction, section 2 provides a very brief description of SMED and of resource constrained scheduling using BAG, showing already the kind of changeover scenarios where this approach can be used. Section 3 describes the implementation in the wooden frame factory. On section 4 the results of this industrial application are analyzed. Finally, on section 5, some conclusions are outlined.

\section{SINGLE MINUTE EXCHANGE OF DIE AND RESOURCE CONSTRAINED SCHEDULING}

The setup time necessary to prepare a given part of a production system (e.g. line or cell) to a different product is a typical example of waste, as no added value is provided during that process, and thus it should be reduced to the lowest possible value. That is the objective of SMED, the well-known technique developed by Prof. Shigeo Shingo [6]. The implementation of SMED starts with a preliminary stage consisting in a previous analysis in order to clearly understand the changeover process, identifying all the setup operations involved. The video recording of a changeover occurrence is very useful, as some characteristics of the setup operations can be easily obtained (e.g. duration and necessary resources). Usually, informal meetings with the involved workers are also necessary to clarify other aspects/characteristics (e.g. technical details and eventual existence of precedence relations). After this preliminary stage, three more stages are necessary to implement SMED: 1) separation of internal and external setup operations, 2) conversion of internal into external setup operations, and, 3) rationalization of all the setup operations.

Unlike the external operations, the internal ones can only be executed if the production equipment is stopped, 
and, thus, it is obvious the importance of the transformation of internal into external setup operations (stage 2). In some cases stage 3 may become complex, but its execution is determinant to achieve relevant setup time reduction. An extensive list of techniques/tools that can be used in each stage can be found in $[6,7]$.

As previously seen, a changeover process implies the execution of a number of setup operations (the number and type depend, obviously, of the changeover process). If the number of setup operations is relevant (e.g. greater than 10), if precedence relations exist, and if there is some kind of limitation in the necessary resources (human and/or material), then the scheduling of those operations may become somewhat difficult. This kind of scenario gathers all the conditions to apply resource constrained scheduling methods, namely the Brooks' algorithm (BAG), which is an heuristic approach based on priority rules, usually applied in the project management area (e.g. $[8,9,10])$. Basically two types of approaches can be used to deal with resource constrained scheduling: heuristic approaches and optimal approaches. Heuristic approaches based on priority rules are intuitive, simple and easy to implement $[4,11]$, facilitating thus the knowledge transfer to the companies and the quick obtention of results. The optimal methods usually have tendency to involve complex models, implying a considerable implementation effort [12]. Therefore, even not assuring an optimal solution, a heuristic approach based on priority rules is the most adequate for the case described in this paper. The BAG was chosen because its results are considered (empirically) by [3] as "consistently good". This algorithm performs the scheduling of project's activities, considering their duration, precedence relations and resources' need, in order to conclude the project in the shortest possible period of time, with a limited set of resources. Thus, when applicable to the quick changeover area, the BAG should allow the scheduling of the setup operations (activities) to conclude the changeover process (project) as fast as possible, with a limited number of workers (resources). The BAG application, after the activities' identification and characterization, involves the following stages: 1) construction of the activities' network (usually an activity-on-arc diagram), 2) establishment of the activities' priority, and, 3) detailed scheduling of the activities (considering the limitation of resources). The activities are sorted by descendent order of their ACTIM value (Activity Control TIMe), and, if necessary (in cases of tie), the algorithm uses the Lang's heuristic [3]. This heuristic sorts the activities by their latest start time (crescent order), float (crescent order), duration (decrescent order) and resources' need (decrescent order).

\section{INDUSTRIAL APPLICATION}

The quick changeover application was carried out in the mentioned wooden frame factory. In a first meeting at the company, the painting line (Fig. 1) was identified as one of the critical sections of the production system.

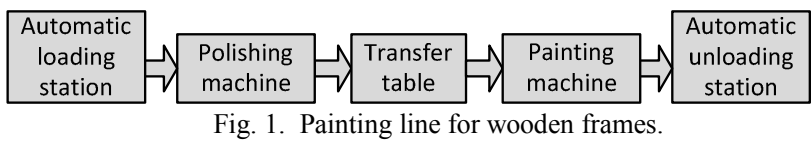

Usually the changeover process requires almost one hour, which is not compatible with the new production needs imposed by the market (small quantities and large diversity). The main equipments are a polishing machine (with five millstones) and a painting machine (with five varnish sprinklers), connected by a roller transfer table. The first machine is fed with raw wooden frame sticks by an automatic loading station and the second is unloaded by another automatic station. This preliminary analysis stage was completed with the video recording of a changeover occurrence which took 51 minutes and was carried out by a single worker. The detailed analysis of the video, complemented with important information provided by the workers, allowed the identification and characterization of all the setup operations (38). Due to line composition (Fig. 1) this set was divided in two subsets, one for the polishing machine (34 operations) and other for the painting machine (4 operations). The automatic loading/unloading stations do not require relevant setup and the transfer table demands a single operation, which, by convenience, was included in the subset associated to the painting machine. All the setup operations were performed with the line stopped (internal operations) but two of them, and part of a third, were easily transformed into external operations. The sprinklers' cleaning, in the painting machine, is an internal operation as there is only one set of these devices - the acquisition of a second set allowed the transformation into an external operation. The other two internal to external transformations were associated to the polishing machine: selection and transportation of the millstones, and selection of the ring spacers necessary to install each millstone (Fig. 2). In the first case, while the line is operating the worker goes to the tools-store to retrieve the millstones necessary for the next wooden frame sticks. In the second case, as the next millstones are already present, the worker can select the appropriate ring spacers (several spares are available). During the last stage of SMED implementation, a second analysis to the changeover video has revealed that the sequence of operations performed by the worker was not the most appropriate, implying an excessive number of movements (the line is almost 15 meters long) and the existence of distinct operations that could otherwise be aggregated.

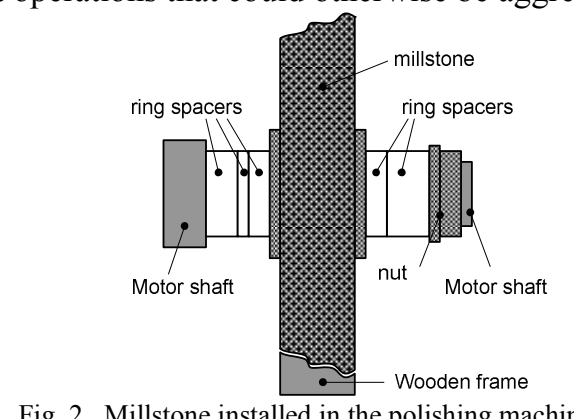

Fig. 2. Millstone installed in the polishing machine. 
The problem is mainly related to the adjustment of the nine alignment devices (each one has several guides and rollers) included in the polishing machine (to guide the wooden frame sticks). A reorganization of internal setup operations was carried out. Table I and Table II present updated internal setup operations for the polishing machine and painting machine, respectively. The initial list of setup operations for the polishing machine had two operations (open and close) for each of the nine alignment devices, because these operations were not performed in sequence. Their sequential execution - besides a reduction in the number of movements - allowed the aggregation into a single operation: adjustment of $i^{\text {th }}$ alignment set (Table I). Another five pairs of setup operations initially identified (removal of $i^{\text {th }}$ millstone and installation $i^{\text {th }}$ millstone) were aggregated into as many single operations: changing of $\mathrm{i}^{\text {th }}$ millstone (Table I).

Unlike the polishing machine case, the initial list of setup operations of the painting machine had very few operations (4), some of them not appropriately aggregated. A disaggregation was performed as it was more appropriate to consider two subsets of sprinklers instead of the entire set at once (Table II).

The implementation of parallel operations (one of the techniques that SMED can use to rationalize setup operations) was particularly adequate to this changeover scenario due to its characteristics (type of operations and physical dimensions of the line). The major inconvenient of this technique - the requirement of additional resources - was not a problem in this case, as the company can easily provide more workers (coming from other factory's sections) whenever a changeover becomes necessary. To implement parallel operations it is necessary a detailed schedule of the setup operations that must be executed by each worker. As previously explained, the BAG can develop that schedule. The algorithm was applied twice: first to the setup operations of the polishing machine and then to the setup operations of the painting machine. The application was conducted accordingly to the stages described in section II. Fig. 3 represents the operations' network of the polishing machine changeover process, in the form of an activity-on-arc diagram (AOA) built from the information in Table I. The fictitious activities F1 to F8 are necessary as in an AOA diagram no more than one activity can begin and end at the same nodes.

TABLE I

INTERNAL SETUP OPERATIONS FOR THE POLISHING MACHINE

\begin{tabular}{rlll}
\hline Op. & Description & Duration $(\min )$ & Precedence \\
\hline A & Adjust. of $1^{\text {st }}$ alignment set & 1.4 & \\
$\ldots$ & $\ldots$ & $\ldots$ & \\
I & Adjust. of $9^{\text {th }}$ alignment set & 1.4 & \\
$\mathrm{~J}$ & Changing of $1^{\text {st }}$ millstone & 2.2 & \\
$\ldots$ & $\ldots$ & $\ldots$ & \\
$\mathrm{N}$ & Changing of $5^{\text {th }}$ millstone & 2.2 & \\
$\mathrm{O}$ & Adjust. of $1^{\text {st }}$ millstone & 1.2 & $\mathrm{~J}$ \\
$\ldots$ & $\ldots$ & $\ldots$ & $\ldots$ \\
$\mathrm{S}$ & Adjust. of $5^{\text {th }}$ millstone & 1.2 & $\mathrm{~N}$ \\
\hline
\end{tabular}

TABLE II

INTERNAL SETUP OPERATIONS FOR THE PAINTING MACHINE

\begin{tabular}{clll}
\hline Op. & Description & Duration (min) & Precedence \\
\hline A & Adjust. of transfer table & 1.0 & \\
B & Adjust. guides paint. mach. & 0.7 & A \\
C & Install. 1 $1^{\text {st }}$ sprinklers' set (3) & 0.8 & \\
D & Install. 2 ${ }^{\text {nd }}$ sprinklers' set (2) & 0.5 & \\
E & Initial adjust. 1 ${ }^{\text {st }}$ sprink. set & 4.8 & $\mathrm{C}$ \\
F & Initial adjust. 2 & \\
Gd & sprink. set & 3.2 & D \\
H & Final adjust. 1 ${ }^{\text {st }}$ sprink. set & 1.8 & E, B \\
\hline
\end{tabular}

The observation of Fig. 3 reveals the existence of five critical paths (J-O, K-P, L-Q, M-R and L-S, with duration of $2.2+1.2=3.4$ minutes), and also the existence of 14 startup operations (A to N). This means that, theoretically, the changeover of the polishing machine could be completed in 3.4 minutes. In practice this is not feasible due to the absurd size of the necessary changeover team (14 workers). The BAG application continued with the obtention of the operations' sequence, which is: $\mathrm{J}, \mathrm{K}, \mathrm{L}$, $\mathrm{M}, \mathrm{N}, \mathrm{A}, \mathrm{B}, \mathrm{C}, \mathrm{D}, \mathrm{E}, \mathrm{F}, \mathrm{G}, \mathrm{H}, \mathrm{I}, \mathrm{O}, \mathrm{P}, \mathrm{Q}, \mathrm{R}, \mathrm{S}$. In practice this means that the first operations should be the changing of the millstones. The number of millstones that can be simultaneously changed is dependent, obviously, of the size of the changeover team. The company proposed a team with three workers for the entire painting line changeover (naturally, two were allocated to the polishing machine and one to the painting machine).

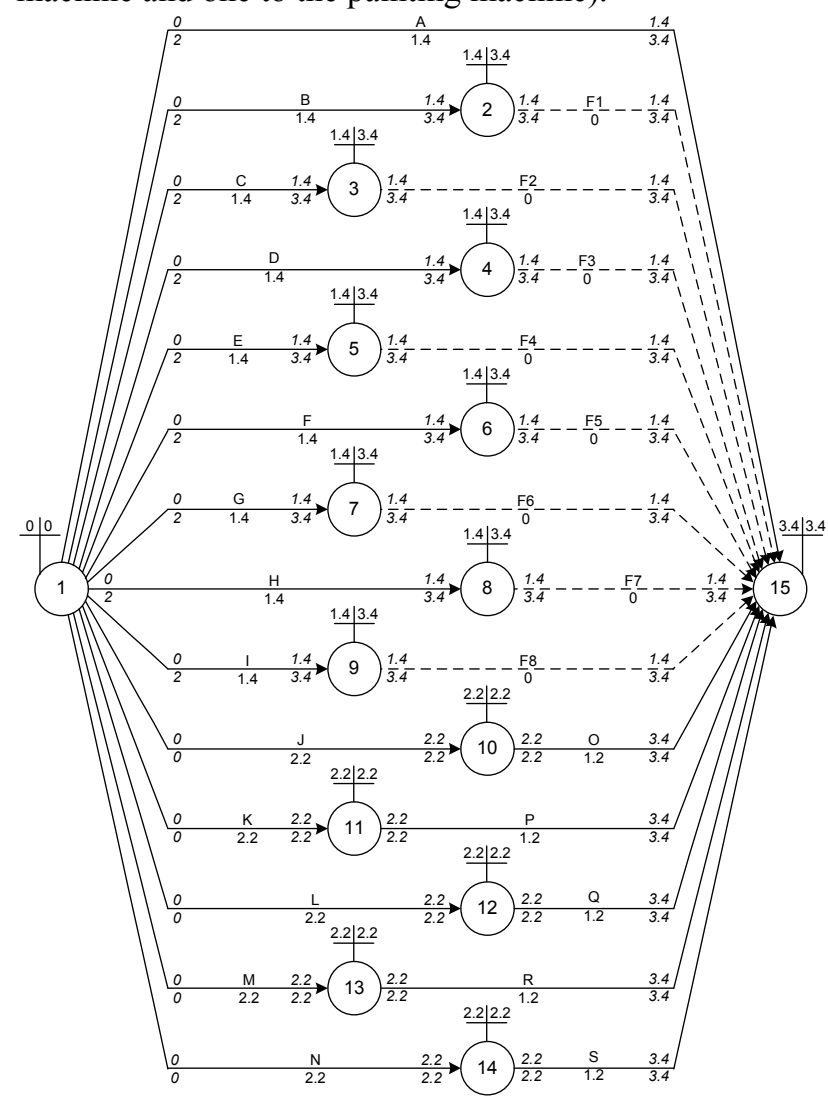

Fig. 3. Network of operations of the polishing machine setup process. 
Thus, with a resource constrain of two workers, the last stage of BAG was applied to the polishing machine. The correspondent result is presented in Table III - a detailed schedule of the entire set of operations which allows the changeover process to be completed in 15 minutes, by a team of two workers.

As previously referred, the BAG was also applied to the painting machine. Fig. 4 represents the operations' network of the painting machine changeover process.

TABLE III

SCHEDULE OF SETUP OPERATIONS FOR THE POLISHING MACHINE

\begin{tabular}{|c|c|c|c|c|c|c|}
\hline Time & Op. & $\begin{array}{l}\text { Durat. } \\
(\mathrm{min})\end{array}$ & Begin & End & $\begin{array}{l}\text { Available } \\
\text { resources }\end{array}$ & $\begin{array}{l}\text { Allowed } \\
\text { operations }\end{array}$ \\
\hline 0 & & & & & 2 & $\begin{array}{l}\text { J,K,L,M,N,A,B,C, } \\
\mathrm{D}, \mathrm{E}, \mathrm{F}, \mathrm{G}, \mathrm{H}, \mathrm{I}\end{array}$ \\
\hline 0 & $\mathrm{~J}$ & 2.2 & 0 & 2.2 & 1 & $\begin{array}{l}\mathrm{K}, \mathrm{L}, \mathrm{M}, \mathrm{N}, \mathrm{A}, \mathrm{B}, \mathrm{C}, \mathrm{D}, \\
\mathrm{E}, \mathrm{F}, \mathrm{G}, \mathrm{H}, \mathrm{I}\end{array}$ \\
\hline 0 & $\mathrm{~K}$ & 2.2 & 0 & 2.2 & 0 & \\
\hline 2.2 & & \multicolumn{3}{|c|}{$\mathrm{J}, \mathrm{K}$ concluded } & 2 & $\begin{array}{l}\text { L,M,N,A,B,C,D,E, } \\
\text { F,G,H,I,O,P }\end{array}$ \\
\hline 2.2 & $\mathrm{~L}$ & 2.2 & 2.2 & 4.4 & 1 & $\begin{array}{l}\text { M,N,A,B,C,D,E,F, } \\
\text { G,H,I,O,P }\end{array}$ \\
\hline 2.2 & M & 2.2 & 2.2 & 4.4 & 0 & \\
\hline 4.4 & & \multicolumn{3}{|c|}{ L,M concluded } & 2 & $\begin{array}{l}\text { N,A,B,C,D,E,F,G, } \\
\text { H,I,O,P,Q,R }\end{array}$ \\
\hline 4.4 & $\mathrm{~N}$ & 2.2 & 4.4 & 6.6 & 1 & $\begin{array}{l}\text { A,B,C,D,E,F,G,H,I } \\
\text {,O,P,Q,R }\end{array}$ \\
\hline 4.4 & A & 1.4 & 4.4 & 5.8 & 0 & \\
\hline 5.8 & & \multicolumn{3}{|c|}{ A concluded } & 1 & $\begin{array}{l}\text { B,C,D,E,F,G,H,I,O } \\
\text {,P,Q,R }\end{array}$ \\
\hline 5.8 & $\mathrm{~B}$ & 1.4 & 5.8 & 7.2 & 0 & \\
\hline 6.6 & & \multicolumn{3}{|c|}{$\mathrm{N}$ concluded } & 1 & $\begin{array}{l}\text { C,D,E,F,G,H,I,O,P } \\
\text {,Q,R,S }\end{array}$ \\
\hline 6.6 & $\mathrm{C}$ & 1.4 & 6.6 & 8 & 0 & \\
\hline 7.2 & & \multicolumn{3}{|c|}{ B concluded } & 1 & $\begin{array}{l}\mathrm{D}, \mathrm{E}, \mathrm{F}, \mathrm{G}, \mathrm{H}, \mathrm{I}, \mathrm{O}, \mathrm{P}, \mathrm{Q} \\
\text {,R,S }\end{array}$ \\
\hline 7.2 & $\mathrm{D}$ & 1.4 & 7.2 & 8.6 & 0 & \\
\hline 8 & & \multicolumn{3}{|c|}{$\mathrm{C}$ concluded } & 1 & $\begin{array}{l}\mathrm{E}, \mathrm{F}, \mathrm{G}, \mathrm{H}, \mathrm{I}, \mathrm{O}, \mathrm{P}, \mathrm{Q}, \mathrm{R} \\
\text {,S }\end{array}$ \\
\hline 8 & $\mathrm{E}$ & 1.4 & 8 & 9.4 & 0 & \\
\hline 8.6 & & \multicolumn{3}{|c|}{ D concluded } & 1 & $\mathrm{~F}, \mathrm{G}, \mathrm{H}, \mathrm{I}, \mathrm{O}, \mathrm{P}, \mathrm{Q}, \mathrm{R}, \mathrm{S}$ \\
\hline 8.6 & $\mathrm{~F}$ & 1.4 & 8.6 & 10 & 0 & \\
\hline 9.4 & & \multicolumn{3}{|c|}{ E concluded } & 1 & $\mathrm{G}, \mathrm{H}, \mathrm{I}, \mathrm{O}, \mathrm{P}, \mathrm{Q}, \mathrm{R}, \mathrm{S}$ \\
\hline 9.4 & G & 1.4 & 9.4 & 10.8 & 0 & \\
\hline 10 & & \multicolumn{3}{|c|}{ F concluded } & 1 & $\mathrm{H}, \mathrm{I}, \mathrm{O}, \mathrm{P}, \mathrm{Q}, \mathrm{R}, \mathrm{S}$ \\
\hline 10 & $\mathrm{H}$ & 1.4 & 10 & 11.4 & 0 & \\
\hline 10.8 & & \multicolumn{3}{|c|}{ G concluded } & 1 & $\mathrm{I}, \mathrm{O}, \mathrm{P}, \mathrm{Q}, \mathrm{R}, \mathrm{S}$ \\
\hline 10.8 & I & 1.4 & 10.8 & 12.2 & 0 & \\
\hline 11.4 & & \multicolumn{3}{|c|}{ H concluded } & 1 & $\mathrm{O}, \mathrm{P}, \mathrm{Q}, \mathrm{R}, \mathrm{S}$ \\
\hline 11.4 & $\mathrm{O}$ & 1.2 & 11.4 & 12.6 & 0 & \\
\hline 12.2 & & \multicolumn{3}{|c|}{ I concluded } & 1 & $\mathrm{P}, \mathrm{Q}, \mathrm{R}, \mathrm{S}$ \\
\hline 12.2 & $\mathrm{P}$ & 1.2 & 12.2 & 13.4 & 0 & \\
\hline 12.6 & & \multicolumn{3}{|c|}{ O concluded } & 1 & $\mathrm{Q}, \mathrm{R}, \mathrm{S}$ \\
\hline 12.6 & Q & 1.2 & 12.6 & 13.8 & 0 & \\
\hline 13.4 & & \multicolumn{3}{|c|}{ P concluded } & 1 & $\mathrm{R}, \mathrm{S}$ \\
\hline 13.4 & $\mathrm{R}$ & 1.2 & 13.4 & 14.6 & 0 & \\
\hline 13.8 & & \multicolumn{3}{|c|}{ Q concluded } & 1 & $\mathrm{~S}$ \\
\hline 13.8 & $\mathrm{~S}$ & 1.2 & 13.8 & 15 & 0 & \\
\hline 14.6 & & \multicolumn{3}{|c|}{$\mathrm{R}$ concluded } & 1 & \\
\hline 15 & & \multicolumn{3}{|c|}{ Changeover concluded } & 2 & \\
\hline
\end{tabular}

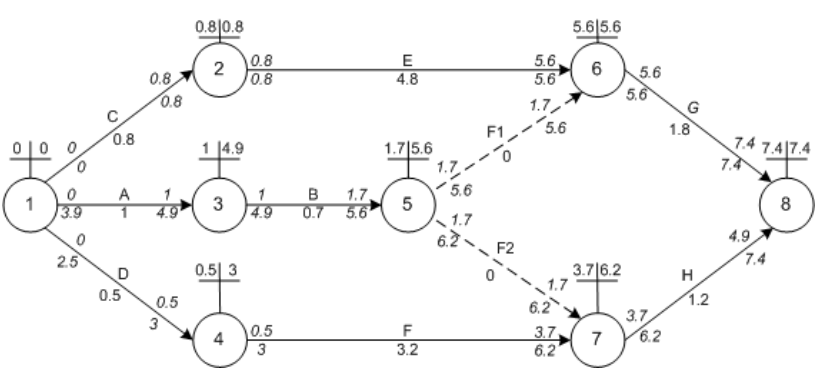

Fig. 4. Network of operations of the painting machine setup process.

In fact, with a single worker the BAG application is not necessary (except, eventually, to determine the operations' sequence) but if more workers can be allocated to the changeover process, then it is worth. The critical path is C-E-G, with duration of $0.8+4.8+1.8=7.4$ minutes, and the startup operations are $\mathrm{A}, \mathrm{C}$ and $\mathrm{D}$. Thus, without constrains in the number of workers, the changeover could be completed in 7.4 minutes (contrarily to the polishing machine, this "theoretical changeover" seems to be feasible).

The operations' sequence obtained accordingly to BAG is: C, E, D, F, A, B, G, H. It is obvious that with a single worker, the changeover process of the painting machine will require 14 minutes (sum of the operations' duration) and, in that case, the construction of the operations' schedule is not relevant. However, under special circumstances, the company might consider the inclusion of more workers in the changeover team (this possibility will be analyzed in the next section). With that perspective in mind, the BAG was applied considering a team of two workers. The resulting detailed schedule is represented in Table IV and shows that the changeover process of the painting machine can be completed in 8.4 minutes by a team of two workers.

TABLE IV

SCHEDULE OF SETUP OPERATIONS FOR THE PAINTING MACHINE

\begin{tabular}{|c|c|c|c|c|c|c|}
\hline Time & Op. & $\begin{array}{l}\text { Duration } \\
\text { (min) }\end{array}$ & Begin & End & $\begin{array}{l}\text { Available } \\
\text { resources }\end{array}$ & $\begin{array}{l}\text { Allowed } \\
\text { operations }\end{array}$ \\
\hline 0 & & & & & 2 & $\mathrm{C}, \mathrm{D}, \mathrm{A}$ \\
\hline 0 & $\mathrm{C}$ & 0.8 & 0 & 0.8 & 1 & \\
\hline 0 & D & 0.5 & 0 & 0.5 & 0 & \\
\hline 0.5 & & \multicolumn{2}{|c|}{ D concluded } & & 1 & $\mathrm{~F}, \mathrm{~A}$ \\
\hline 0.5 & $\mathrm{~F}$ & 3.2 & 0.5 & 3.7 & 0 & \\
\hline 0.8 & & \multicolumn{2}{|c|}{ C concluded } & & 1 & $\mathrm{E}, \mathrm{A}$ \\
\hline 0.8 & E & 4.8 & 0.8 & 5.6 & 0 & \\
\hline 3.7 & & \multicolumn{2}{|c|}{ F concluded } & & 1 & A \\
\hline 3.7 & A & 1 & 3.7 & 4.7 & 0 & \\
\hline 4.7 & & \multicolumn{2}{|c|}{ A concluded } & & 1 & B \\
\hline 4.7 & B & 0.7 & 4.7 & 5.4 & 0 & \\
\hline 5.4 & & \multicolumn{2}{|c|}{ B concluded } & & 1 & $\mathrm{H}$ \\
\hline 5.4 & $\mathrm{H}$ & 1.2 & 5.4 & 6.6 & 0 & \\
\hline 5.6 & & \multicolumn{2}{|c|}{ E concluded } & & 1 & $\mathrm{G}$ \\
\hline 5.6 & G & 1.8 & 5.6 & 8.4 & 0 & \\
\hline 6.6 & & \multicolumn{3}{|c|}{$\mathrm{H}$ concluded } & 1 & \\
\hline 8.4 & & \multicolumn{3}{|c|}{ Changeover concluded } & 2 & \\
\hline
\end{tabular}




\section{ANALYSIS OF RESULTS}

The changeover of the painting line observed (and recorded in video) in the factory, took 51 minutes and was carried out by a single worker. SMED was applied and, in the preliminary stage, an initial set of 39 setup operations was identified. Two internal operations, and part of a third, were transformed into external operations, resulting in an immediate reduction of 7.4 minutes in the changeover time. Problems were identified in the sequence of the internal setup operations and a reorganization process was performed - 28 operations associated to the polishing machine were transformed into 14 aggregated operations and the 5 operations associated to the painting machine were disaggregated into 8 operations. The reorganization resulted in a set of 27 operations (Table I, Table II) but, obviously, had no influence in the changeover duration. To reduce this duration, the concept of parallel operations was implemented (the company wanted to avoid large monetary investments, but had some human resources' availability). The Brooks' algorithm (BAG) was applied considering a team of 3 workers, resulting in a detailed schedule which allowed the changeover of the painting line to be achieved in 15 minutes. In special cases (e.g. priority situations) the size of the changeover team could be increased to 5 elements ( 3 for the polishing machine and 2 for the painting machine) - in this case the entire changeover process can be completed in 10.2 minutes (result not developed in this paper). From the academic viewpoint, and somehow by curiosity, the application of BAG considering a team of 7 workers indicates a changeover duration of 7.4 minutes. In a more pragmatic perspective, two A3 placards with the detailed schedule of the setup operations, in the form of a Gantt chart, were developed to be placed in the painting line: the first one for the "normal" changeover (3 workers, 15 minutes) and the second for the "express" changeover (5 workers, 10.2 minutes).

\section{CONCLUSION}

The objectives defined in the introduction were achieved: the industrial application was successful and the effective utilization of the resource constrained scheduling in the ambit of SMED, using the Brooks algorithm (BAG), was demonstrated.

The company's expectations were accomplished - the changeover process of the painting line was significantly improved, almost without monetary investment (only the acquisition of a second set of sprinklers for the painting machine). The company was accustomed to produce large quantities of wooden frames and thus, due to the new markets' tendencies, its stock become huge (hundreds of $\mathrm{Km}$ of wooden frames, representing hundreds of thousands of Euros). The improvement of the painting line changeover process is an important contribution towards the reduction of that stock.

In terms of future developments, at least two improvements can be introduced in the polishing machine, having as immediate consequence the reduction of the duration of the changeover process: the actual mechanism to hold each millstone (Fig. 2) should be replaced by a functional clamp device (e.g. spring stops or split thread) and the adjustment of the nine alignment sets could be automated. The main problem of these proposals, especially of the second one, is probably the associated cost. Additionally, but without influence in the changeover process duration, the painting machine could be equipped with a mechanism to automatically detect the obstruction of the sprinklers (avoiding thus the continuous presence of a worker). Finally, the use of other approaches (including both heuristic and optimal) for resource constrained scheduling could be explored.

\section{REFERENCES}

[1] J. H. Gilmore, B. J. Pine Ii, "The Four Faces of Mass Customization," Harvard Business Review, 75(1): 91, 1997.

[2] A. Mousavi , P. Adl, R. T. Rakowski,A. Gunasekaran, "Design of a Production Planning System Using Customer Oriented Design and Resource Utilisation (CODARU)," The International Journal of Advanced Manufacturing Technology, vol. 17, no. 11, pp. 805-809, 2001.

[3] D. D. Bedworth, J. E. Bailey, Integrated Production Control Systems: Management, Analysis, Design. 2nd ed.: John Wiley \& Sons, 1987.

[4] R. Kolisch, "Serial and parallel resource-constrained project scheduling methods revisited: Theory and computation," European Journal of Operational Research, vol. 90, pp. 320-333, 1996.

[5] P. Costa, A. Alves, R. Sousa, "Implementação da Metodologia Quick Changeover numa Linha de Montagem Final de Auto-Rádios: para além da Técnica SMED," in $5^{\circ}$ Congresso Luso-Moçambicano de Engenharia, J. F. S. Gomes, C. C. António, C. F. Afonso \& A. S. Matos, Maputo - Moçambique, Edições INEGI, 03A004.1-8, 2008.

[6] S. Shingo, A Revolution in Manufacturing: The SMED System. Portland, Oregon: Productivity Press, 1985.

[7] "Quick Changeover for Operators". Portland, Oregon, Productivity Press, 1996.

[8] H. Kerzner, Project Management: A Systems Approach to Planning, Scheduling, and Controlling. John Wiley and Sons, 1998.

[9] J. Lewis, Project Planning, Scheduling and Control: A Hands-On Guide on Bringing Projects In on Time and on Budget. McGraw-Hill, 1995.

[10] M. Rosenau, Successful Project Management: A Step-byStep Approach with Practical Examples. John Wiley and Sons, 1998.

[11] P. Brucker, A. Drexl, R. Mohring, K. Neumann, E. Pesch, "Resource-constrained project scheduling: Notation, classification, models, and methods," European Journal of Operational Research, vol. 112, pp. 3-41, 1999.

[12] G. Whitehouse, G. DePuy, "Solving constrained multiple resource networks both forward and backward using Brooks algorithm," Project Management Journal, vol. 32, no. 4, pp. 24-31, 2001. 